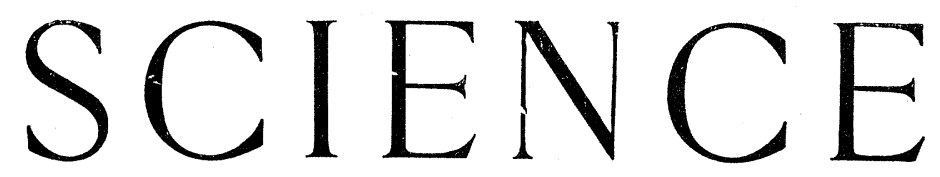

NEW YORK, APRIL 28, 1893.

\section{THE TOPOGRAPHIC MAPS OF THE UNITED STATES GEOLOGICAL SURVEY.}

BY W. M. DAVIS, HARVARD COLlege, CAMBRIDGe, MASS.

OuR national Geological Survey was charged by Congress with the preparation of a geological map of the United States. As no suitable topographic map existed to serve as the base of geological coloring, the Director of the Survey proceeded to develop a topographic corps for the purpose of producing a map that should serve his needs. This action has from time to time called forth discussion; as, for example, recently in The American Geologist. Information on the subject from the standpoint of the several scientific governmental bureaus may be found in the "Testimony before the Joint Commission of Congress," in 1885. It is not my intention to discuss this subject here, as I have been more interested in the examination of the great geographical product of the Survey, than with the association of geographical work with one bureau of the government or another. The recent appearance of the first folio of the "Geologic Atlas of the United States," marking the beginning of a most important national publication, without parallel in magnitude in other countries, makes some account of the topographic maps of the Survey appropriate at the present time.

The first season of topographic field-work under the re organized survey was in 1882. Previous surveys had done much work in the West; but their styles of publication were discordant. Belts of litoral country had been mapped by the Coast Survey; similar belts along the Great Lakes had been mapped by the Lake Survey; and extensive maps were in progress under the Mississippi and Missouri River commissions. The areas covered by these various surveys and by the topographic division of the Geological Survey are indicated in the annual reports of the Director. No duplication of earlier work of acceptable character has been attempted; but the results gained by ali the surveys are reduced to a uniform style of publication, on a plan that will in time embrace the entire country.

Details of the plan adopted for the topographic survey are presented in the annual report of the Director for 1884-85. Our country includes an area of $3,000,000$ square miles; hence the need of economy. The elaborate methods applicable in smaller European nations could not be introduced. An astronomical and computing division took charge of the determination of fundamental points, where needed. A triangulation division extended the determination of points from those furnished by the astronomical parties or from previous work by the Coast or other Surveys. The Appalachian triangulation, for example, is illustrated in the sixth annual report of the Survey. While this triangulation suffices for the needs of the proposed maps, it is not of such accuracy as would be required in determining the figure of the earth; being in this respect different from the fundamental triangulations of our Coast Survey and of most foreign countries. The saving of time and money, demanded in the survey of so great an area, required this modification of former methods. Numerous topographical parties were placed in the field to fill in the spaces between the smaller triangles. The plane table was employed in many districts; traverse surveying was adopted elsewhere. Railroad levels have been extensively utilized. Much sketching between established points has been required; and to any one who carries the published maps into the tield, it will be apparent that the details of topographic form are generalized, and are occasionally incorrectly represented on account of the rapidity with which the work was carried on. It was difficult at first, as it may be still, to secure the services of a sufficient number of experienced topographers; but their practice in the field has added to their expertness in sketching streams, ridges, and contours. Much effort has been given to their improvement practical field instruction has been given to the newer men during the summer months, and voluntary meetings for discussion of methods have been held during the winter in Washington.

Those who wish to examine the style of work followed in the preparation of various sample sheets, should consult the eighth annual report, in which $\mathrm{Mr}$. Gannett has included several graphic illustrations of the number and distribution of points determined by intersections, or of lines run by traverse. Yet it is manifest that much is left to sketching, and, judging from the amount of country covered by a single party in a season's work, the sketching must often be rapid.

In common with many others, I wish that the accuracy of the surveys might have been greater; but I presume that all questions of method, scale, style, cost, and equitable distribution of work were duly considered by Major Powell, Director, Mr. Gannett, Geographer, and other members of the Survey, and decided as seemed best in view of all controlling circumstances. Not least among these controls is the disposition of Congress to support the work. Judging by the appropriations recently voted, it would take the greater part of a century to survey the country by the more elaborate European methods. Our grandchildren and not ourselves would enjoy the products of the work, and few of us are so unselfish as to be satisfied with so long a postponement.

As to publication, three scales were at first adopted; $1: 62,500$; 1: 125,000; and 1:250,000; corresponding to about one, two and four miles to the inch. The map-sheets were divided according to lines of latitude and longitude, a sheet on the smallest scale covering a "square degree," while four and sixteen sheets of the larger scales are required for the same area. Each sheet is named after its chief town and State; and on the later sheets, the name of the four sheets adjoining it are printed on its sides: the four corner-wise sheets might be to advantage indicated in the same way. According to the scale of the map and the complication of the topography, contours are drawn with vertical intervals varying from 10 to 200 feet. Each sheet is printed in three colors, as described in the sixth annual report: black for the artificial features and names, all lettering following a consistent plan; blue for the hydrography, brown for the contours. All the sheets thus far issued are printed very clearly, and as a rule accurately; the earlier ones by Bien of New York, the latter ones by the Survey itself.

According to information lately received from Mr. Gannett, the number of sheets completed up to June 30,1892, is as follows: 295 on scale of $1: 62,500 ; 338$ on $1: 125,000$; and 61 on $1: 250,000$; making a total of 694 . The total area surveyed, but not all engraved, to that date was 547,000 square miles, distributed over forty-two States and Territories. In future, only the inch-to-a-mile scale will be employed, and the surveys of the current year are conducted with regard to this new feature of the plan.

Before speaking of certain sheets of the contoured maps, mention should be made of several smaller scale maps of the country as a whole. The most important of these is the nine-sheet map, on a scale of $1: 2,500,000$, with contours for $100,500,1000,1500$, 2000 , and higher thousands of feet.

A limited edition of this map has been prepared for office use without the black print of artificial features and names, thus giving desirable prominence to the natural features. This is an 
extremely valuable map, as it contains all available information concerning the relief of our country, expressed in a form most generally useful. A smaller sheet, including the whole country, represents increasing altitude by a series of nine brown tints; a very effective presentation destined to serve as the original of many a map in our school geographies.

A visit to the office of the Survey in Washington discloses the great fund of information there gathered on the topographic mapsheets. Unhappily the sheets are not at present published for general distribution; they are chiefly for the use of the members of the Survey in their geological studies. The edition of each sheet as printed is stored in a room containing a great number of shelves, each one marked in front with the name of its map. Hardly a sheet can be drawn from its shelf without revealing some interesting features to the geographer, the geologist, or the engineer.

It is only of the first of these interests that I shall speak. Although when examined on the ground that they represent, the maps are not so accurate in detail as we might wish, still the graphic view of the country that they present is so vastly more minute than any to which we have hitherto had access that it is something of a revelation to look over them. A great fund of geographical information is stored up in that map-room. One may look forward to an auspicious geographical day when the maps are generally distributed, and when that universal study, home geography, is enriched by the illustrations that they will afford. Some of the smaller eastern States have already reached this happy position, by means of two-party arrangements between themselves and the national Survey. The first of these was New Jersey. After the Coast Survey had furnished the triangulation, and after about half of the mapping had been borne by the State, the Geological Survey sustained the remainder of the cost of field-work; but in this State, the form of publication is somewhat different from that adopted for the rest of the country. The sheets are larger, and overlap to a considerable extent, so that there is no place that is not well within the boundary of one sheet or another. The publication of the seventeen inch-to-amile sheets and of the shaded relief map of the State on a scale of five miles to an inch, has been duly noted in Science at the time of their appearance. The separate sheets may be obtained from the State Geological Survey for 25 cents a piece, or $\$ 5$ for the complete atlas of twenty sheets. Massachusetts was the next State to take advantage of the two-party arrangement. The triangulation here was taken chiefly from the old Borden survey. Now the whole State is covered in 54 inch-to-a-mile sheets; and a four-sheet map, on a scale of four miles to an inch with contours every hundred feet, has been published. Like the New Jersey atlas, the 54 sheets of Massachusetts may be bought of the Commissioners (address, Commonwealth Building, Boston) for six dollars. Composites of the sheets about Boston and Worcester have been published by the Appalachian Mountain Club for use in field excursions and otherwise. Rhode Island is next to be mentioned. Here the area is so small that the several sheets covering the State, with parts of Massachusetts and Connecticut next adjoining, have been mounted on rollers, and through the active interest of the State Commissioners, the local Legislature has been induced to make a special appropriation of $\$ 3,500$ for the distribution of the mounted map to all public schools and libraries within the State, - a wise and liberal step towards better public education. The mounted map is also sold by J. C. Thompson, Providence, at $\$ 2$ a copy. It is manifest that large States may follow this plan, by mounting grouped sheets in roller maps about four by five feet; so that every school should be provided with a large map of its own part of the State. If one may judge by the small appreciation that teachers generally have of the physical features of their own regions, such a distribution of maps is greatly needed.

In other parts of the country, there are no States completely mapped as yet. A large area of country has been covered along the central and southern Appalachians, and the first folio of the Geologic Atlas was a map from this district, with others soon to follow. Missouri and Kansas have the good fortune to be represented by a large number of contiguous sheets; and in the west- ern States and Territories the maps of the older surveys have been redrawn and printed on the new uniform plan. The various lines of interest suggested by these maps would lead me to write many pages, were they all followed; and I shall therefore limit myself here to the one which takes my first attention, the physical features of our home geography. This may be illustrated by a brief reference to five maps from Missouri,--the Tuscumbia, Versailles, Warsaw, Clinton, and Butler sheets.

These sheets run from east to west, partly across the central part of the State, somewhat south of the Missouri River, and include the greater part of the basin of the Osage River. The eastern course of the Osage, towards its mouth in the Missouri, is seen to be extremely tortuous in a steep-sided valley, trenched two or three hundred feet below the level of the surrounding upland. The meanders of the river are peculiar in not being, like those of the Mississippi, spread upon a flat flood-plain. High spurs of the upland occupy the neck of land between every turn of the stream. Evidently, the meanders are not of the ordinary type. It has been suggested that they result from the jointed structure of the rocks that the river traverses; but this is hardly possible, for it would not explain the manifest relation that exists between the size of the river and the radius of its swinging curves: the larger the stream, the larger the radius. I have therefore supposed that we have in this curiously curved valley an illustration of a process long recognized in the case of various rivers of northern France. Briefly stated, this is as follows: Once upon a time, a river, long active, had worn down its basin to a surface of faint relief. Its valley sides had wasted away so as to oppose little interference to its lateral swinging. Its slope had become very gentle, and its current had taken to a deviating path, peculiar to old streams, which so generally meander on their flat flood-plains. Then the region that it traversed was evenly raised to a greater altitude, and the faithful stream once more turned to the task of cutting down its channel close to base-level and carrying away all the waste that was fed into it. But in doing so, it retained in the new cycle of its life the meandering course that it had attained in its old age in the previous cycle. Although its activities were rejuvenated, its habit of swinging from side to side was still preserved. It behaves as if it were on a flood-plain, although the flood-plain, on which it learned this behavior, has been consumed. The Seine and Meuse have extremely meandering channels in deep and rather steep-sided valleys; and I have learned from my most obliging and wellinformed correspondent, Mr. E. de Margerie, that the above explanation is current regarding them. The Mosel also has a deep meandering gorge between the Eifel and the Hunsrück, in western Germany. In this country, I have supposed that the meanders of the north branch of the Susquehanna, in the plateau of northeastern Pennsylvania, might be thus explained; and the incredible turns of the unpronounceable Connedogwinit, opposite Harrisburg, seem to be of the same kind, except that the Susquehanna learned its swinging habit on a Cretaceous lowland floodplain, while the Connedog winit was taught in late Tertiary times. On looking over the Missouri maps, I concluded that the Osage was another example of the same inherited habit; and in this case there is a neat little bit of confirmation on the western of the map-sheets named above that deserves mention.

If it is true that the curved course. of the Osage is inherited from a flood-plain whose level lay across the top of the present valley when the land lay lower, we must suppose that, after gaining elevation to the present altitude, and thus gaining permission to cut down towards a new base-level, advantage would be taken of this permission first in the lower part of the river, and that the deepening of the channel would gradually work backwards up stream. Good fortune brought us upon the river while it is, as we may say, just in the act of thus adjusting its valley to the new altitude of its drainage area. We see the lower course already deepened, while the upper course still preserves its part of the flood-plain from which the curves of the lower river were inherited. The upper branches of the Osage flow upon broad flood-plains meandering freely, skirted by back-swamps, and frequently cutting off their curves and leaving ox-bow lakes to one side of their newer course. These upper branches preserve 
what the lower part of the river has already lost: they tell us what it has been, while it foretells what they shall come to be.

Of course, while only the maps are before me, and the Osage is a long thousand miles away, I do not wish to assert that this sketch of its history is demonstrably true; although I am strongly persuaded that an examination of the region on the ground would discover evidence confirmatory of it. The upland is built of nearly horizontal Paleozoic rocks. If they had stood at their present height above the sea ever since the date of their deposition, they would now be worn down close to sealevel, without retaining any distinct relief. Their narrow valleys show that this supposition is out of the question. The rolling upland in which the narrow valleys are incised is itself a surface of denudation; and as its reliefs are faint, with long gentle slopes and broad open valleys, beneath whose floor the narrow deeper valleys are incised, I am driven to the belief that the upland was for a long time a lowland, and that its gentle eminences are merely the remnants of a once higher mass. The dates at which this older denudation was carried on, and the later date at which the uplift to its new altitude was given, are not well determined; although from analogy with more eastern parts of the country, where the dates of such changes have been better made out, I am inclined to say that the Missouri upland was a lowland well into Tertiary time; and that the new trenches of the Osage and its neighbors were begun in consequence of an uplift somewhere about the close of Tertiary time.

These are suggestions rather than conclusions; but they still serve to illustrate the incentive to geographical study that the topographic maps supply. We all knew that there was a fertile field for study in our home geography; every one in his own district enjoyed cultivating his patch of the field; but now through the publication of these maps, it is as if the whole field was opening to all of us; and a rich geographical product is promised to all who enter it.

\section{SUN-HEAT AND ORBITAL ECCENTRICITY.}

\section{BY ELLEN HAYES, WELLESLEY, MASS.}

THE reader of Sir Robert Ball's important work, "The Cause of an Ice Age," needs no reminder that its argument rests upon a foundation of theoretical astronomy. To secure the essentials of the discussion one must read between the lines. It is the object of the present paper to select and arrange a few of the more simple inter-linear readings, in the hope that they may be serviceable in that borderland where astronomy, geology, and meteorology have each a claim.

1. "There can be no doubt that when the eccentricity is at its highest point the earth is, on the whole, rather nearer the sun, because, while the major axis of the ellipse is unaltered, the minor axis is least." ("The Cause of an Ice Age," p. "79). This is equivalent to saying that the mean distance of the earth from the sun is a function of the eccentricity of the earth's orbit, and is, moreover, such a function that when the eccentricity is a maximum the function is a minimum. The mean or average length of the radius-vector of an ellipse depends on the law assumed in regard to its variation. From the standpoint of geometry, disregarding kinematical and dynamical considerations, the simplest assumption is, that the vectorial angle is the fundamental variable. If the equation to the ellipse be written

$$
r=\frac{a\left(1-e^{2}\right)}{1+e \cos \theta}
$$

and $r^{\prime}$ be the mean length of the radius-vector, we may easily show that

$$
\boldsymbol{r}^{\prime}=\frac{1}{\pi} \int_{0}^{\pi} r d \theta=a \sqrt{1-e^{2}} .
$$

But in any investigation dealing with the amount of light or heat received by the earth a different assumption should be made; for it is clear that if the earth moves most slowly when in aphelion the effect is the same as if it were, on the whole, farther away from the sun. Assuming that the time is the fundamental variable and that the radius-vector sweeps over equal areas in equal times, we may find the average of the radii-vectores corresponding to the successive equal time-intervals. Consider a point moving in a circle whose centre is one focus of the ellipse. Let its areal velocity be equal to that of the point describing the ellipse, and suppose that when the radius-vector of the ellipse has swept through $180^{\circ}$, the radius, $r_{0}$, of the circle has swept through the same angle. Then

$$
r_{0}^{2} \frac{d \theta_{0}}{d t}=r^{2} \frac{d \theta}{d t}=2 c=\frac{\pi a^{2} \vee \overline{1-e^{2}}}{T},
$$

where $2 T$ is the periodic time. Integrating between the limits $0^{\circ}$ and $180^{\circ}$

$$
\pi r_{0}^{2}=\pi a^{2} \sqrt{1-e^{2}}, \text { or } r_{0}=a \sqrt[4]{1-e^{2}} .
$$

$r_{0}$ is thus a minimum when $e$ is a maximum, and vice versa. The value $r_{0}$ in (2) is greater than the value $r^{\prime}$ in (1), as we might have known in advance by simply comparing the two assumptions respecting the law of variation of $r$.

Developing the factor

$$
\sqrt[4]{1-e^{2},} \quad r_{0}=a\left(1-\frac{e^{2}}{4}-\frac{3 e^{4}}{32}-\ldots\right) .
$$

The present eccentricity of the earth's orbit is 0.01678. According to Leverrier it cannot exceed 0.077747. To take $r_{0}=a$, the average of $a(1+e)$ and $a(1-e)$, that is, of the aphelion and perihelion distances, is therefore a close approximation to the mean value obtained with the assumptions above made. Laplace, in stating Kepler's third law, says, "The squares of their times of revolution are as the cubes of the transverse axes of their ellipses." (Méc. Cél., II., i., §3). He uses the term "mean distance" in speaking of the satellites of Jupiter and Saturn, but not in such a way as to indicate that he meant the semi-major axis. Gauss, in his first mention of the semi-major axis, says, "Hinc semiaxis major, qui etiam distantia media vocatur, fit $=\frac{p}{1-e e}$ ". (“Theoria Motus," p. 4). Similarly, Sir John Herschel uses the terms "mean distance" and "semi-major axis" as interchangeable.

2. "The total quantity of heat which the earth receives during each complete revolution will be inversely proportional to the minor-axis of the ellipse." (p. 79). Let $d h$ be the heat-increment received in the time $d t$, and $\mu$ the rate of variation of heat at a unit's distance. Then, since the quantity of heat received varies directly as the time and follows the law of the inverse square,

$$
d h=\mu \frac{d t}{r^{2}} .
$$

But from Kepler's second law,

$$
\begin{gathered}
r^{2} \frac{d \theta}{d t}=2 c, \text { or } \frac{r^{2}}{d t}=\frac{2 c}{d \theta} . \text { Hence } \\
h=\int_{0}^{\pi} \frac{u d \theta}{2 c}=\frac{\mu \pi}{2 c}
\end{gathered}
$$

From this it appears that the quantity of heat received in passing from one end of the major-axis around to the other varies inversely as the areal velocity. But

$$
2 c=\frac{\pi a^{2} \sqrt{1-e^{2}}}{T}
$$

and since the length of the year is constant and the major-axis is constant, the areal velocity is to be viewed as a function of $e$ alone. Suppose $e$ becomes $e^{\prime}$ and let $c^{\prime}$ denote the new value of the areal velocity. Then $h^{\prime}=\frac{\mu \pi}{2 c^{\prime}}$, and therefore $h: h^{\prime}:: c^{\prime}: c$. But $c: c^{\prime}:: b: b^{\prime} ;$ hence $h: h^{\prime}:: b^{\prime}: b$. Again, if we substitute $\frac{\pi a b}{T}$ for $2 c$ in (3),

$$
h=\frac{\mu \pi T}{\pi a b}=\frac{\mu T}{a^{2} \sqrt{1-e^{2}}}
$$

Hence the amount of heat received in one year is the same that would be received if the earth were to move for a year in a cirole whose radius is $a \sqrt[4]{1-e^{2}}$. 